\title{
Identifying needs and expectations of potential users of the virtual platform to foster healthy and active ageing in Andalusia
}

Sandra Pinzón ${ }^{1}$, Mónica Padial Espinosa ${ }^{1}$, Bibiana Navarro Matillas ${ }^{1}$, Juan Manuel Espinosa Almendro² ${ }^{2}$ Pilar San Juan Lozano ${ }^{3}$ and Luz López Samaniego ${ }^{3 *}$

${ }^{1}$ Andalusian School of Public Health, Spain

${ }^{2}$ El Palo Primary Care Centre, Spain

${ }^{3}$ Regional Ministry of Health of Andalusia, Spain

\begin{abstract}
The governance approach is being applied in Andalusia to the development of the Public Health Law. This approach understands the context, the needs and expectations of the people to whom public policies are aimed to and try to achieve with them the most appropriate solutions. One experience of establishing this approach has been the design of a virtual platform for the promotion of active ageing: enbuenaedad. 570 persons were consulted. Focus groups, community forums, and professional forums were used to collect the information. 1,811 expectations were analyzed related to the contents, formats and utilities of the web platform. Older people expressed the need of simplicity and clarity of the format of the interfaces, tutorials and a step by step style of navigation. The results achieved in each phase are returned to the participants through a web container. This contributes to the clarity and transparency of the process. The effectiveness of the application of this approach has been demonstrated with the rapid acceptance of the virtual platform by older people.
\end{abstract}

\section{Governance and public health}

Governance represents a cooperative form of government in which public institutions and civil society participate actively in the formulation and application of public policies [1]. Governance is tangible. It is not just a matter of style. Governance translates into facts, is orderly, transparent and clear [2].

This approach is being aimed to the development of the Public Health Law in the region of Andalusia. Since its promulgation in 2011, the Regional Ministry of Health of Andalusia has placed special emphasis on the effective participation of citizens and professionals in the design and implementation of public health interventions [3]. One of the priority interventions is aimed at the promotion of active and healthy ageing [2]. In this area the Regional Ministry of Health of Andalusia opted for the use of information and communication technologies (ICT) to improve the quality of life of people as they get older. The design of a virtual platform to foster active and healthy ageing was proposed. Needs and expectations of older people and professionals, such as potential users of the web portal, were identified previously to the development of the design [4-6]. The objective was to understand the context, expectatives and needs of older people in order to develop with them the most appropriate technological solutions.

\section{Context}

To know the relationship of older people with ICT data from the survey of the Institute of Statistics and Cartography of Andalusia (IECA, 2015). In 2007 only $6 \%$ of people over 65 years used Internet. In 2014 this figure reached until 26\%. The most frequent uses were through messages of the App WhatsApp, also search for information, especially news, health issues or training activities.
To go further qualitative research with two focus groups were carried out. Participants affirmed the smartphone is fully integrated into their daily lives. They remarked they behave like "linear" navigators, which means that they need to go step by step, and that they do not like to explore. It could be complex for them if the navigation does not respond to that logic. They also express their expectation to be able to get access to the information from a virtual platform which could also be considered as "official and confident". They hoped the platform would allow them to easily find the information they are looking for with a safe navigation.

\section{Needs and expectations}

To identify the needs and expectations of the potential users of the virtual platform 8 community forums and 2 professional forums were held. 363 persons from all over Andalusia participated in the community forums. $60.3 \%$ of participants were women and $39.7 \%$ men. $28.5 \%$ of participants belonged to the group interval from 55 to 64 years, and $17.8 \%$ to the group over 65 years. Participants represented different sectors: the Public Health Administration (23.1\%); citizens (21.5\%); health, social and educational services (16.8\%); City Councils and Provincial Councils (9.6\%). \%); and Associations (7.4\%).

${ }^{\star}$ Correspondence to: Luz López Samaniego, Regional Ministry of Health of Andalusia, Seville, Spain, Tel: +34 653548657, E-mail: luz.lopez.ext@ juntadeandalucia.es

Key words: governance, information and communication, technologies, older adults, social participation, public health

Received: September 10, 2018; Accepted: September 12, 2018; Published: September 17, 2018 
These expectations were grouped into six areas: social participation and leisure; learning, lifestyle; information; health care; security, and affectivity (Picture 1). Regarding the platform's design, 365 expectations were collected and grouped into: simplicity and clarity of the format (35\%); use of audiovisual content (25\%); availability of tutorials (19\%); guarantee of accessibility for people with functional diversity (11\%); availability of communication tools (5\%); and participation (5\%).

Two professional forums were also convened. In one of them, named Scientific Committee, 20 health professionals participated including both directors of Integral Plans and primary care professionals. In the other one, named Partnership Committee, participated 29 professionals representing the public administration, private companies, the social economy sector, the university and research centres. During these two forums 264 expectations were collected and grouped into the four pillars of active ageing (Table 1 and Figure 1).

The process of analyzing expectations has been clear and orderly. Obtained results of each phase have been communicated to the participants through a web container; thus contributing to the transparency of the process. The needs and expectations of older people became technical requirements for the design of the web platform. After the prototypes were developed started the validation phase.

\section{Design validation}

To validate the prototypes, the community forums (108 participants), the Scientific Committee (14 professionals) and the Partnerships Committee (24 professionals) were called again. A total of 532 expectations were collected, which were refined and classified into 17 categories.

The contributions focused on improving accessibility by increasing the size of the letter, more intuitive labeling, improving iconography, rationalizing the use of colors, reducing the buttons on the main menu, promoting the use of filters and search engines, inclusion of pictures in which the target population felt more recognized with, and videos with text and audio.

Expectations regarding the contents were grouped into the four pillars of active ageing: health, security, participation and lifelong learning. In the field of health, the focus was on having communication access with health professionals, tools for the management of appointments and medication control, and information about resources. Regarding security pillar the focus placed on local and national police advice. Participation included the territorial location of social activities and easy access to available resources. And last but not least, lifelong learning remarked expectations to find courses on healthy lifestyle and self-esteem.

\section{Conclusions}

Constant consultation with the different groups of potential users of the virtual platform enbuenaedad allowed the research group to develop a design that is adapted to their needs and expectations. For the cooperative construction of this intervention, face-to-face (forums) and virtual communication channels (web container) have been necessary. These spaces of communication add clarity and transparency to the process. The effectiveness of this approach has been demonstrated by the rapid acceptance of the web platform and the thousands of visits it receives weekly.

\section{Funding}

Funding from the European Regional Development Fund (ERDF)

Full operation title in original language: TIC. Salud Pública. Envejecimiento Activo. / ICT. Public Health. Active Ageing (English translation)

Table 1. Professionals' expectations about the platform content

\begin{tabular}{|c|c|c|c|c|c|c|}
\hline \multirow{2}{*}{ Committee } & \multicolumn{4}{|c|}{ Active Ageing Pillars } \\
\cline { 2 - 6 } & Health & Security & Participation & Learning & Others \\
\hline Partnership & 65 & 33 & 41 & 18 & 17 \\
\hline Scientific & 43 & 0 & 18 & 56 \\
\hline Total & 108 & 33 & 59 & 55 \\
\hline
\end{tabular}

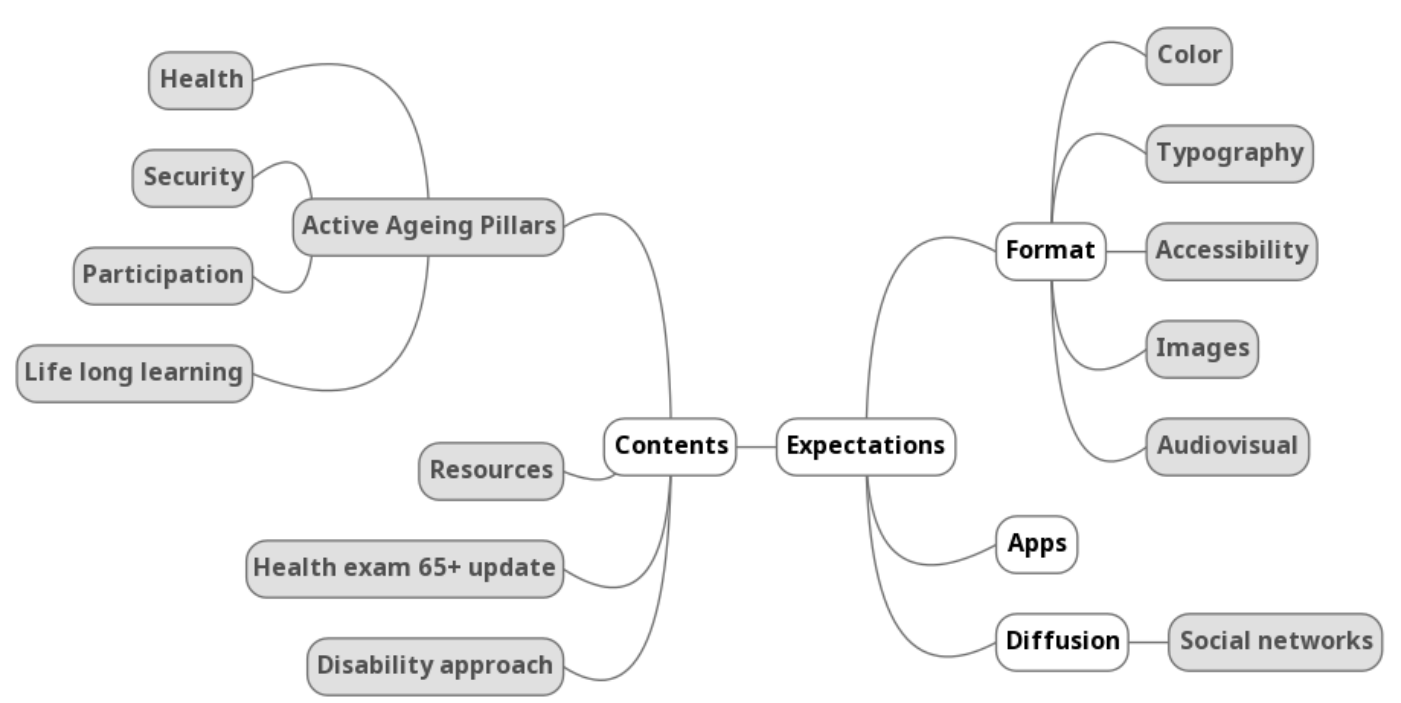

Figure 1. Expectatives from the forums 


\section{Code: A1231081S00006}

Amount: 1,050,000 euros (One million fifty thounsand euros); Period: January 2016-Desember 2020.

\section{References}

1. Nachmias D, Sened I (2001) Governance and public policy. Israel Affairs 7: 3-20.

2. García-Lizana F, Castro-Rodríguez M, Carantoña E (2016) Análisis de la estrategia de la ooperación para la Innovación Europea sobre el Envejecimiento Activo y Saludable y su impacto en España. Logros y propuestas de mejora para el periodo 2016-2020. Madrid.
3. Sánchez Bursón JM (2012) La Gobernanza en la Nueva Ley de Salud Pública en Andalucía. RevistaeSalud.com 8: 1-16.

4. Stav E, Walderhaug S, Mikalsen M, Hanke S, Benc I (2013) Development and evaluation of SOA-based AAL services in real-life environments: A case study and lessons learned. Int J Med Inform 82: e269-e293.

5. Instituto de estadística y cartografía de Andalucía. [Internet] Consejería de Economía y Conocimiento. [cited 2018 September 10]

6. Rotberg RI (2015) On Governance. What it is, what it measures, and its policy uses Canadá: Centre for International Governance Innovation.

Copyright: @2018 Pinzón S. This is an open-access article distributed under the terms of the Creative Commons Attribution License, which permits unrestricted use, distribution, and reproduction in any medium, provided the original author and source are credited. 